\title{
Amorphous silica nanoparticles aggregate human platelets: potential implications for vascular homeostasis
}

\author{
J Jose Corbalan ${ }^{1,2}$ \\ Carlos Medina' \\ Adam Jacoby ${ }^{2}$ \\ Tadeusz Malinski \\ Marek W Radomski' \\ 'School of Pharmacy and \\ Pharmaceutical Sciences, Faculty \\ of Health Sciences, Panoz Institute, \\ Trinity College Dublin, Ireland; \\ ${ }^{2}$ Department of Chemistry and \\ Biochemistry, Ohio University, \\ Athens, $\mathrm{OH}$, USA
}

This article was published in the following Dove Press journal:

International Journal of Nanomedicine

3 February 2012

Number of times this article has been viewed
Background: Amorphous silica nanoparticles (SiNP) can be used in medical technologies and other industries leading to human exposure. However, an increased number of studies indicate that this exposure may result in cardiovascular inflammation and damage. A high ratio of nitric oxide to peroxynitrite concentrations $\left([\mathrm{NO}] /\left[\mathrm{ONOO}^{-}\right]\right)$is crucial for cardiovascular homeostasis and platelet hemostasis. Therefore, we studied the influence of SiNP on the platelet $[\mathrm{NO}] /\left[\mathrm{ONOO}^{-}\right]$balance and platelet aggregation.

Methods: Nanoparticle-platelet interaction was examined using transmission electron microscopy. Electrochemical nanosensors were used to measure the levels of $\mathrm{NO}^{-}$and $\mathrm{ONOO}^{-}$ released by platelets upon nanoparticle stimulation. Platelet aggregation was studied using light aggregometry, flow cytometry, and phase contrast microscopy.

Results: Amorphous SiNP induced NO release from platelets followed by a massive stimulation of $\mathrm{ONOO}^{-}$leading to an unfavorably low $[\mathrm{NO}] /\left[\mathrm{ONOO}^{-}\right]$ratio. In addition, SiNP induced an upregulation of selectin P expression and glycoprotein IIb/IIIa activation on the platelet surface membrane, and led to platelet aggregation via adenosine diphosphate and matrix metalloproteinase 2-dependent mechanisms. Importantly, all the effects on platelet aggregation were inversely proportional to nanoparticle size.

Conclusions: The exposure of platelets to amorphous SiNP induces a critically low $[\mathrm{NO}] /\left[\mathrm{ONOO}^{-}\right]$ratio leading to platelet aggregation. These findings provide new insights into the pharmacological profile of SiNP in platelets.

Keywords: amorphous silica nanoparticles, nanotoxicology, nitric oxide, peroxynitrite, platelet aggregation

\section{Introduction}

It is increasingly recognized that engineered amorphous silica nanoparticles (SiNP) may have important implications for vascular homeostasis. We have recently demonstrated the ability of SiNP to induce endothelial cell dysfunction linked to increased peroxynitrite $\left(\mathrm{ONOO}^{-}\right)$production. ${ }^{1}$ As human blood platelets along with endothelium play a critical role in vascular homeostasis, we have now examined the biocompatibility of amorphous SiNP (10 nm, 10SiNP; $50 \mathrm{~nm}, 50 \mathrm{SiNP} ; 150 \mathrm{~nm}, 150 \mathrm{SiNP} ; 500 \mathrm{~nm}$, 500SiNP) with human platelets.

The vascular NO, synergistically with prostacyclin, inhibits platelet activation and aggregation. ${ }^{2-5}$ This vasorelaxant and platelet regulator is essential for vascular homeostasis and an impairment of NO bioavailability is one of the earliest events in vascular diseases. ${ }^{6,7}$ Superoxide anion reacts rapidly with $\mathrm{NO}$ producing $\mathrm{ONOO}^{-}$, a major component of oxidative stress, rapidly decreasing NO bioavailability. ${ }^{8}$ 
A high $\mathrm{ONOO}^{-}$production and depleted $\mathrm{NO}$ availability resulting in a low ratio of maximal $\mathrm{NO}$ to maximal $\mathrm{ONOO}^{-}$ concentrations $\left([\mathrm{NO}] /\left[\mathrm{ONOO}^{-}\right]\right.$) can be accurately used as an indicator of nitroxidative/oxidative stress and dysfunction of the cardiovascular system. ${ }^{1,9-11}$ The high $[\mathrm{NO}] /\left[\mathrm{ONOO}^{-}\right]$balance is essential for maintaining platelet regulation, as high amounts of $\mathrm{ONOO}^{-}$counteract the platelet-inhibitory effects of NO leading to platelet activation and aggregation. ${ }^{12}$

In the current studies, a direct release of $\mathrm{NO}$ and $\mathrm{ONOO}^{-}$ during nanoparticle-platelet interactions was measured electrochemically by nanosensors. The NO generation by platelets was followed by a greater $\mathrm{ONOO}^{-}$production leading to a low $[\mathrm{NO}] /\left[\mathrm{ONOO}^{-}\right]$ratio. Indeed, we demonstrated that amorphous SiNP induced activation of the glycoprotein $\mathrm{IIb} / \mathrm{III}$ (GPIIb/IIIa) and expression of the selectin P (SELP) on the platelet surface membrane leading to platelet activation and aggregation. The activation of GPIIb/IIIa is triggered off by the release of major platelet activators that mediate pathways of aggregation such as thromboxane $\mathrm{A}_{2}\left(\mathrm{TXA}_{2}\right){ }^{13}$ adenosine diphosphate (ADP) ${ }^{14}$ and matrix metalloproteinase 2 (MMP2) $)^{15}$ which amplify aggregation. Our studies showed that SiNP induce platelet aggregation via stimulation of ADP and MMP2 released from platelets.

\section{Materials and methods Reagents}

All reagents were purchased from Sigma-Aldrich (Arklow, Ireland) unless otherwise indicated. Engineered amorphous SiNP with different sizes $(10 \mathrm{~nm}, 50 \mathrm{~nm}, 150 \mathrm{~nm}$, and $500 \mathrm{~nm}$ ) were purchased from Polysciences (Eppelheim, Germany).

\section{Zeta potential measurement}

The zeta potentials of all the SiNP were determined by a Zetasizer Nano ZS (Malvern Instruments, Malvern, UK). Measurements were performed six times for each particle size $(100 \mu \mathrm{g} / \mathrm{mL}$ in ultrapure water) at room temperature.

\section{Transmission electron microscopy (TEM) of SiNP}

Nanoparticle suspensions (10 $\mu \mathrm{g} / \mathrm{mL}$ in ultrapure water) were examined by a JEM 2100 transmission electron microscope (JEOL, Herts, UK). The diameter of 100 nanoparticles of each size on three TEM micrographs was measured by ImageJ an open-source, Java-based imaging software (http:// rsbweb.nih.gov/ij/).

\section{Isolation of human platelets}

Blood was obtained from healthy volunteers who had not taken any drugs known to affect platelet function for 2 weeks prior to the study. Washed platelets were obtained as described previously. ${ }^{16}$ Briefly, blood was collected and anticoagulated using trisodium citrate $(3.15 \% \mathrm{w} / \mathrm{v} ; 9: 1 \mathrm{v} / \mathrm{v})$. The citrated blood was centrifuged at room temperature to prepare platelet-rich plasma (PRP). Washed platelets were prepared by centrifugation of PRP, containing prostacyclin at room temperature. Following isolation, platelets were resuspended in prostacyclin-free Tyrode's salt solution. Washed platelet concentrations were adjusted using Tyrode's salt solution to a final concentration of $2.5 \times 10^{8}$ platelets per milliliter.

\section{Aggregation studies}

Immediately before use, commercial stock suspensions of SiNP were sonicated for 2 minutes and nanoparticle dispersions in Tyrode's salt solution were prepared by serial dilution from these stock suspensions by vortexing. We tested the effect of different SiNP (10SiNP, 50SiNP, 150SiNP and $500 \mathrm{SiNP}$ ) at different concentrations (1 to $200 \mu \mathrm{g} / \mathrm{mL}$ ).

Platelets were incubated for 2 minutes at $37^{\circ} \mathrm{C}$ in a whole blood/optical lumi-aggregometer (model 700; Chrono-Log, Manchester, UK) prior to the addition of nanoparticles to test spontaneous aggregation. Platelet aggregation was studied for 15 minutes against blanks (Tyrode's salt solution) containing the same particle concentration as the test tubes. Collagen was used as a positive control for platelet aggregation studies. Aggregation data was analyzed by Chrono-Log AGGRO-LINK 8 sofware. ${ }^{17-19}$

Selective platelet aggregation inhibitors (acetylsalicylic acid [ASA], phenanthroline, and apyrase) were added to test tubes. After 1 minute, SiNP were added to the appropriate test tubes.

\section{TEM of human platelets}

Platelet aggregation was terminated at $30 \%$ maximal response, as determined using an aggregometer, in platelets exposed to $10 \mu \mathrm{g} / \mathrm{mL}$ 10SiNP. Unstimulated (resting) platelets were also prepared. Samples were fixed by mixing them with an equal volume of $3 \%$ glutaraldehyde in $0.1 \mathrm{M}$ phosphate buffer for 1.5 hours at room temperature. After primary fixation, samples were centrifuged and pellets washed six times with phosphate buffer. Then, pellets were post-fixed with $2 \%$ osmium tetroxide in phosphate buffer for 30 minutes. Pellets were then dehydrated in a series of graded ethanol solution, infiltrated and embedded in agar 100 epoxy resin, using propylene oxide as a transitional fluid. Next, ultrathin sections 
were cut from dried blocks with a diatom diamond knife on a LKB ULTRATOM III (LKB, Uppsala, Sweden), stained with $0.5 \%$ aqueous uranyl acetate followed by Reynold's lead citrate. Finally, sections were examined by a JEM 2100 transmission electron microscope.

\section{Measurement of $\mathrm{NO}$ and $\mathrm{ONOO}^{-}$ concentrations using nanosensors}

Concurrent $\mathrm{NO}$ and $\mathrm{ONOO}^{-}$measurements were performed with electrochemical nanosensors (diameter: 300-500 nm). The designs are based on previously developed and wellcharacterized chemically modified carbon-fiber technology. ${ }^{20,21}$ Each of the sensors was made by depositing a sensing material on the tip of the carbon fiber: conductive film of polymeric nickel (II) tetrakis (3-methoxy-4hydroxyphenyl) porphyrinic for the NO sensor ${ }^{20}$ and a polymeric film of Mn (III)-paracyclophanyl-porphyrin for the $\mathrm{ONOO}^{-}$ sensor $^{22}$. Amperometry was used to measure changes in $\mathrm{NO}$ and $\mathrm{ONOO}^{-}$concentrations from its basal level with time (detection limit of $1 \mathrm{nM}$ and resolution time $<10 \mu$ s for each sensor). Linear calibration curves were constructed for each sensor from $5 \mathrm{nM}$ to $3 \mu \mathrm{M}$ before and after measurements with aliquots of $\mathrm{NO}$ and $\mathrm{ONOO}^{-}$standard solutions, respectively. Measurements were performed into platelet suspensions. We tested the effect of different SiNP (10SiNP, 50SiNP, 150SiNP, and 500SiNP) at different concentrations (1 to $200 \mu \mathrm{g} / \mathrm{mL}$ ).

\section{Selectin P and GPIlb/llla analyses by flow cytometry}

Flow cytometry was performed using a FACSArray ${ }^{\mathrm{TM}}$ bioanalyzer (Becton, Dickinson and company [BD], Oxford, UK) on single stained platelet samples as described previously. ${ }^{17,23}$ Briefly, to analyze SELP expression, platelet aggregation was terminated at 30\% maximal response, as determined using an aggregometer, in platelet exposed to different SiNP (10SiNP, 50SiNP, 150SiNP, and 500SiNP) at different concentrations (1 to $200 \mu \mathrm{g} / \mathrm{mL}$ ). Platelet suspensions and anti-selectin-P antibody (BD) were then mixed and incubated in the dark at room temperature for 5 minutes. Platelets were identified by forward and side scatter signals, and 10,000 plateletspecific events were analyzed by the flow cytometer for fluorescence.

To analyze GPIIb/IIIa activation, platelet aggregation was terminated at 30\% maximal response, as determined using an aggregometer, in platelets exposed to different SiNP as above. Platelet suspensions and PAC-1 antibody (BD) were mixed and incubated in the dark at room temperature for 15 minutes. Afterwards, an APC Rat Anti-Mouse IgM (secondary antibody) was added and samples incubated in the dark at room temperature for another 15 minutes. Platelets were identified by forward and side scatter signals, and 10,000 platelet-specific events were analyzed by the flow cytometer for fluorescence.

Nonactivated and activated platelets were gated so as not to analyze platelet aggregates. Silica nanoparticles were not detected by the bioanalyzer.

\section{Statistical analyses}

All data are presented as group of means \pm standard error of the mean of $n>3$. Statistical analysis of the mean difference between multiple groups was determined by one-way ANOVA followed by Tukey-Kramer multiple comparison tests; and between two groups by two-tailed Student's $t$-tests. The alpha level for all tests was 0.05 . A $P$ value $<0.05$ was considered to be statistically significant. All statistical analyses were performed using GraphPad Prism (version 5.00 for Windows; GraphPad Software, San Diego, CA) and Origin (version 6.1 for Windows; OriginLab, Northampton, MA).

\section{Results}

\section{Nanoparticle characterization}

In order to confirm the commercially-provided nanoparticle size, we used TEM to measure the size of SiNP. The TEM analysis of 10SiNP, 50SiNP, 150SiNP, and 500SiNP resulted in sizes of $10.50 \pm 0.19 \mathrm{~nm}, 52.67 \pm 0.66 \mathrm{~nm}, 148.20 \pm 2.19 \mathrm{~nm}$, and $495.90 \pm 5.87 \mathrm{~nm}$, respectively. ${ }^{1}$ Furthermore, Zetasizer reported high negative zeta potentials (more negative than $-30 \mathrm{mV}$ ) for all SiNP tested in ultrapure water. ${ }^{1}$

\section{Silica nanoparticle-platelet interaction}

We studied nanoparticle-platelet interactions and uptake using TEM (Figure 1). Electron micrographs showed amorphous SiNP forming agglomerates. These agglomerates were located within platelet aggregates, dispersed among platelets and interacting with the plasma membrane (Figure 1B-D). Nanoparticles also internalized and distributed into the platelet cytoplasm (Figure 1C and D). We also observed degranulated platelets indicating platelet activation (Figure $1 \mathrm{C}$ and D).

\section{Silica nanoparticles induce} a $[\mathrm{NO}] /\left[\mathrm{ONOO}^{-}\right]$imbalance in platelets Using electrochemical nanosensors, we examined in situ, real-time dynamic interaction of amorphous SiNP with human platelets by measuring directly $\mathrm{NO}$ and $\mathrm{ONOO}^{-}$ 

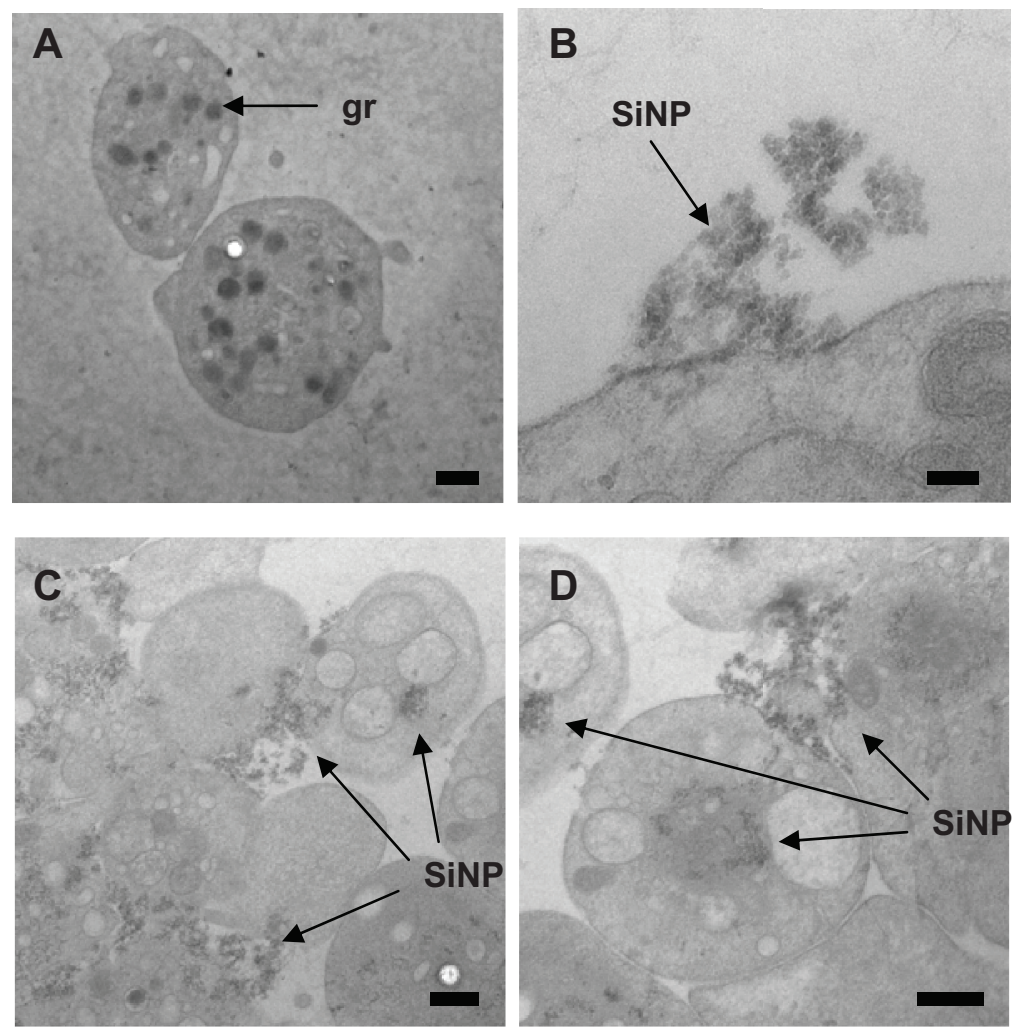

Figure I Amorphous SiNP interact with human platelets. As shown by TEM, after exposure of human platelets to IOSiNP (I0 $\mu \mathrm{g} / \mathrm{mL})$, nanoparticles rapidly interacted with the platelet surface membrane (B) and induced aggregation (C and $\mathbf{D})$. Unstimulated (resting) platelets were also presented (A).

Notes: Scale bars represent $500 \mathrm{~nm}$ in A, C, and D; and $100 \mathrm{~nm}$ in B.

Abbreviations: SiNP, silica nanoparticles; gr, platelet granule; TEM, transmission electron microscopy.

concentrations in a platelet suspension. We demonstrated with time resolution better than $10 \mu$ s that after collision with platelets, these nanoparticles rapidly stimulated NO release (Figure 2B) followed by a greater production of $\mathrm{ONOO}^{-}$. An increased $\mathrm{ONOO}^{-}$production was observed when nanoparticle concentration was increased and size decreased (Figure 2C). The exposure of human platelets to SiNP induced an unfavorable shift of the ratio of [NO]/ $\left[\mathrm{ONOO}^{-}\right]$, as nanoparticle size decreased. Indeed, $10 \mu \mathrm{g} / \mathrm{mL}$ 10SiNP induced a greater decrease in $[\mathrm{NO}] /\left[\mathrm{ONOO}^{-}\right]$than an equal concentration of 50SiNP (Figure 2D). Moreover, 50SiNP $(100 \mu \mathrm{g} / \mathrm{mL})$ induced a lower ratio than an equal concentration of larger nanoparticles (Figure 2E).

\section{Silica nanoparticles induce platelet aggregation}

We studied the ability of SiNP to induce platelet aggregation. Our results demonstrate that amorphous SiNP induce activation of GPIIb/IIIa as well as expression of SELP in the platelet surface membrane (Figure 3A and B). Importantly, platelet receptor activation and expression was inversely proportional to nanoparticle size and directly proportional to particle concentration. Indeed, the smallest nanoparticles (10SiNP) induced GPIIb/IIIa activation and SELP expression when used at a low concentration $(10 \mu \mathrm{g} / \mathrm{mL})$. In contrast, an equal concentration of larger nanoparticles (50SiNP, 150SiNP, and 500SiNP) did not influence platelet receptors. However, when used at a high concentration $(100 \mu \mathrm{g} / \mathrm{mL})$, 50SiNP induced both GPIIb/IIIa activation and SELP expression. Moreover, $200 \mu \mathrm{g} / \mathrm{mL} 150 \mathrm{SiNP}$ and 500SiNP induced SELP expression.

Furthermore, we demonstrated that amorphous SiNP directly induce platelet aggregation and that this effect is greater when nanoparticle size decreases and particle concentration increases (Figure 3C). Indeed, 10SiNP induced platelet aggregation when used at a concentration of $10 \mu \mathrm{g} / \mathrm{mL}$ or higher. Also, 50SiNP and 150SiNP induced platelet aggregation when used at a concentration of $100 \mu \mathrm{g} / \mathrm{mL}$ and $200 \mu \mathrm{g} / \mathrm{mL}$, respectively. However, 500SiNP did not induce platelet aggregation even when used at a very high concentration of $200 \mu \mathrm{g} / \mathrm{mL}$.

Knowing that 10SiNP at $10 \mu \mathrm{g} / \mathrm{mL}$ were able to induce platelet aggregation, further experiments with selective inhibitors of the pathways leading to platelet aggregation mediated 


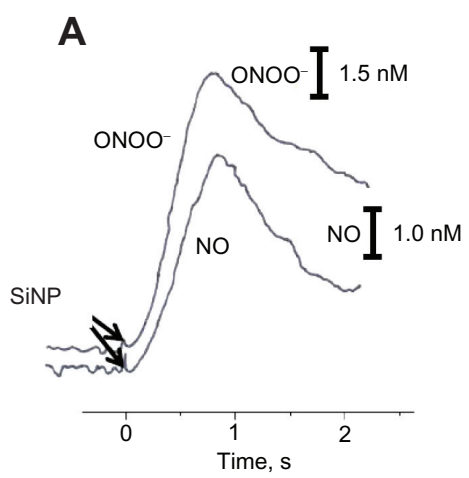

B

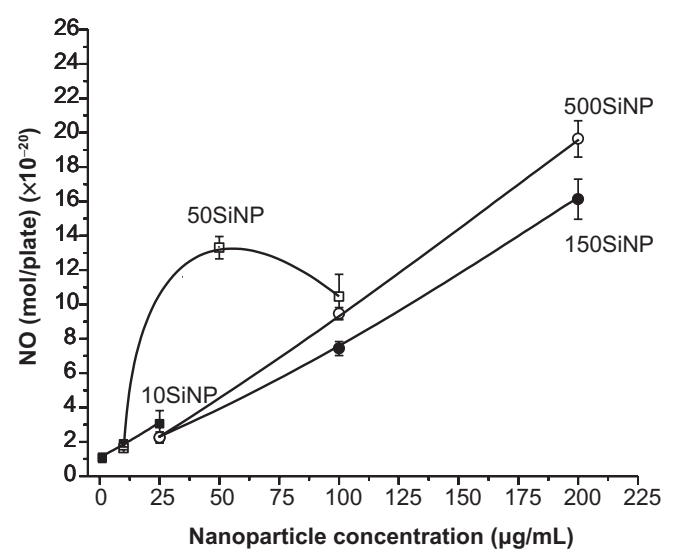

D

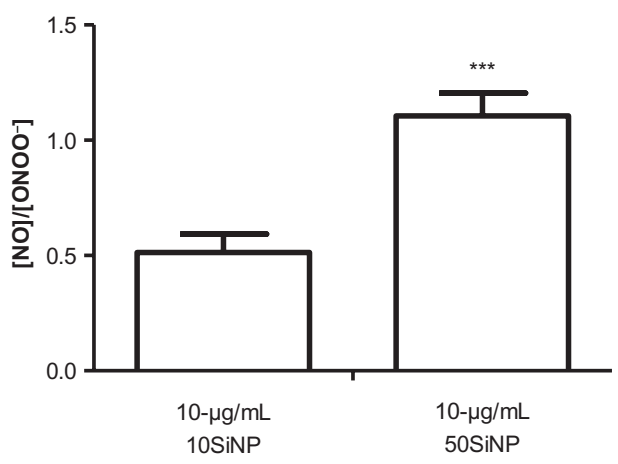

C

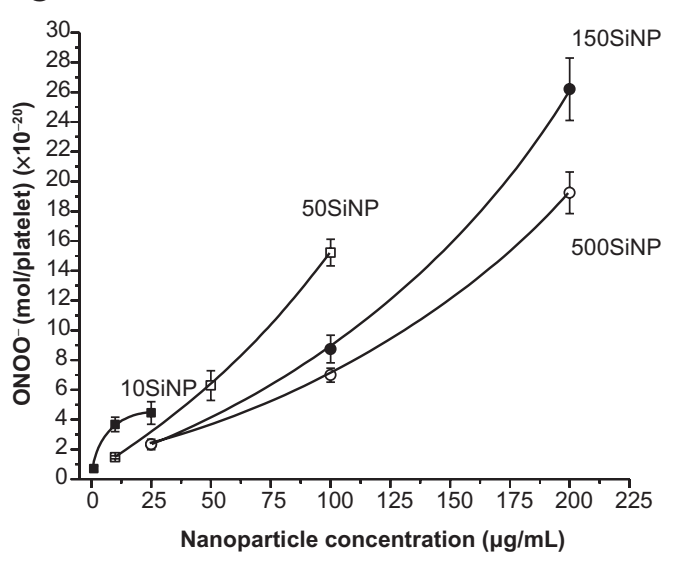

E

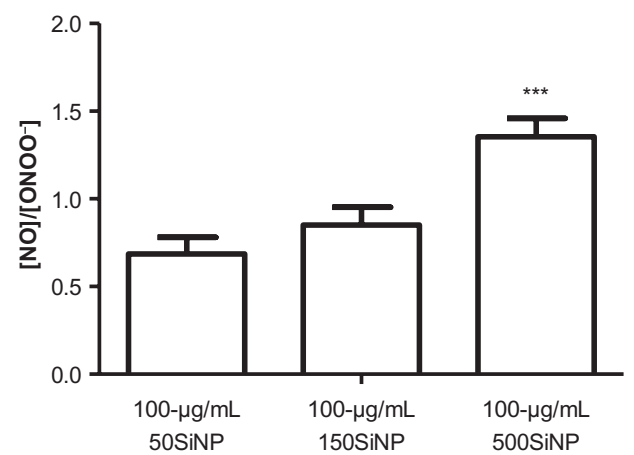

Figure 2 Amorphous SiNP induce $\mathrm{NO}$ and $\mathrm{ONOO}^{-}$production and unfavorably shift the [NO]/[ONOO-] balance in human platelets. (A) Representative recordings of $\mathrm{NO}^{-}$ and $\mathrm{ONOO}^{-}$measured in situ by specific nanosensors after the addition of $10 \mu \mathrm{g} / \mathrm{mL} 10 \mathrm{SiNP}$ to the platelet suspension $\left(2.5 \times 10^{8}\right.$ platelets per milliliter). (B and C) Maximal

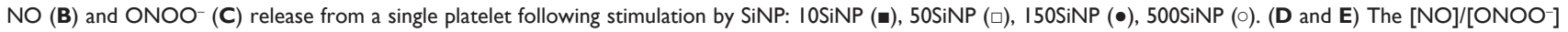
ratio of the maximal $\mathrm{NO}$ and $\mathrm{ONOO}^{-}$concentrations measured upon stimulation of platelets by SiNP at $10 \mu \mathrm{g} / \mathrm{mL}$ (D) and $100 \mu \mathrm{g} / \mathrm{mL}$ (E).

Notes: All values are mean \pm standard error of the mean (SEM) of $n=4$. One-way ANOVA and Tukey-Kramer multiple comparison tests were used for analysis (B and C). All values are mean \pm SEM of $n=4$. Two-tailed Student's $t$-test: $* * * P<0.001$ compared with $10 \mu g / m L ~ I 0 S i N P(D)$. One-way ANOVA and Tukey-Kramer multiple comparison test: $* * * P<0.001$ compared with $100 \mu \mathrm{g} / \mathrm{mL} 50 \mathrm{SiNP}(\mathbf{E})$.

Abbreviations: SEM, standard error of the mean; SiNP, silica nanoparticles.

by TXA 2 (ASA), ADP (apyrase), and MMP2 (phenanthroline) were carried out to characterize the mechanism of SiNP-induced platelet aggregation (Figure 3D). Our results show that incubation of platelets with both phenanthroline and apyrase, but not ASA, prior to their exposure to nanoparticles, inhibited nanoparticle-induced platelet aggregation (Figures 3D and 4).

\section{Discussion}

Platelets and endothelial cells are crucial for the correct maintenance of vascular homeostasis. To exert their function, platelets survey the vascular system and adhere where alterations of the endothelial cell lining, accompanied or not by exposure of subendothelial matrix components, are detected. ${ }^{24}$ 
A

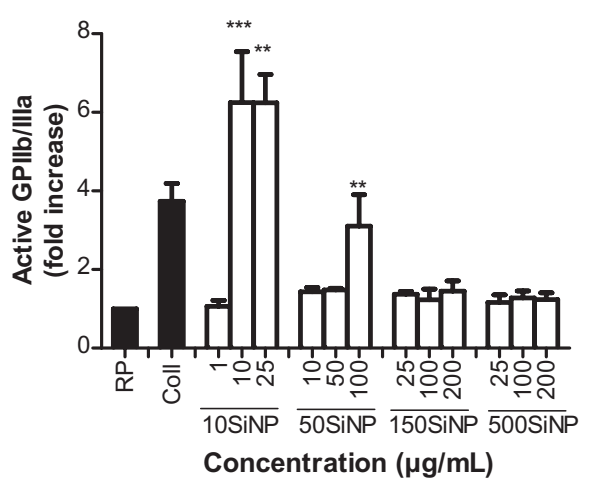

C

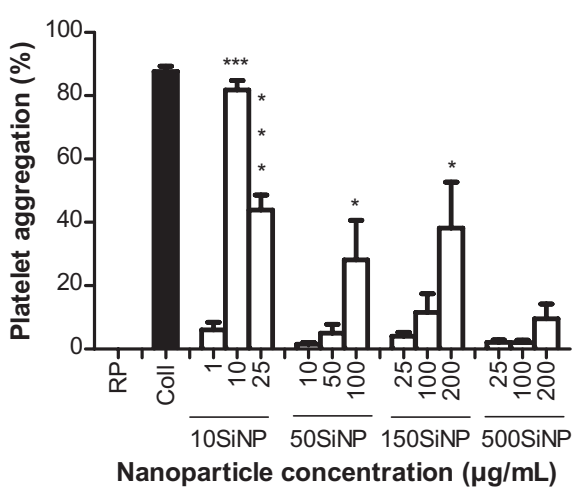

B

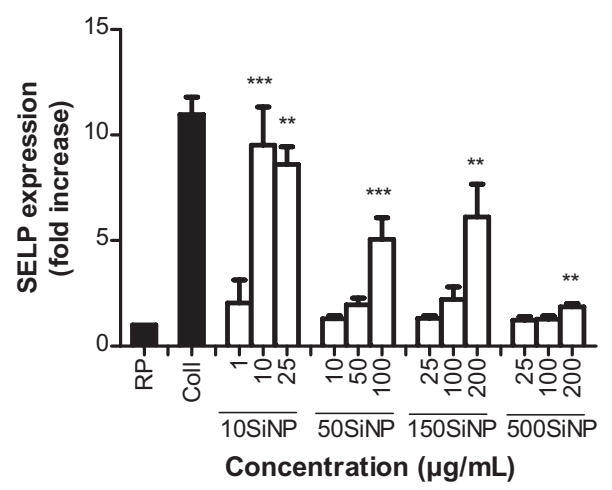

D

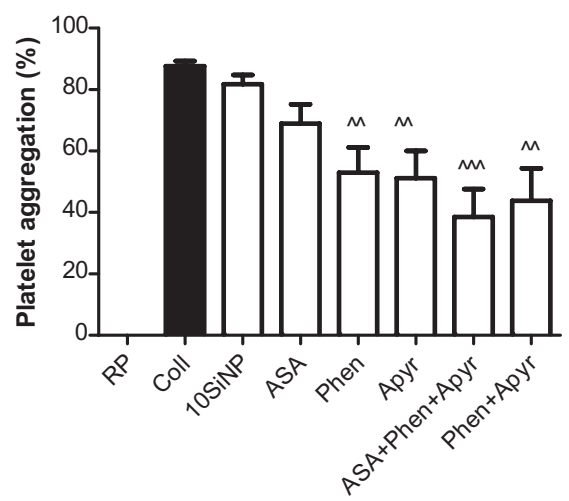

Figure 3 Amorphous SiNP upregulate surface receptors and induce platelet aggregation. Nanoparticles induce GPIIb/llla activation (A), SELP expression (B), and platelet aggregation (C). The use of phenanthroline (Phen) and apyrase (Apyr), but not acetylsalicylic acid (ASA), inhibits IOSiNP-induced platelet aggregation (D). A mixture of these three inhibitors also inhibited nanoparticle-induced platelet aggregation (D). Collagen (Coll) was used as a positive control for platelet aggregation. The GPIlb/llla activation (A) and SELP expression (B) induced by each nanoparticle treatment is expressed relative to unstimulated (resting) platelets.

Notes: All values are mean \pm SEM of $n=4$. One-way ANOVA, Tukey-Kramer post test: $* P<0.05$; $* * P<0.01$; $* * * P<0.00$ I compared with resting platelets (RP) (A-C). One-way ANOVA, Tukey-Kramer post test: ${ }^{\wedge \wedge P}<0.01$; ${ }^{\wedge \wedge \wedge P}<0.001$ compared with $10 \mu \mathrm{g} / \mathrm{mL}$ IOSiNP (D).

Abbreviations: SEM, standard error of the mean; SiNP, silica nanoparticles.

On the other hand, by the secretion or surface expression of a series of specific molecules (NO, prostacyclin), endothelial cells ensure that under normal conditions blood flow is appropriately regulated and that intravascular platelet activation and blood coagulation are avoided.

The deleterious effect of SiNP on endothelial cells found in our previous work ${ }^{1}$ prompted us therefore to study the effect of SiNP on human platelets. In this current study, we found that amorphous SiNP when interacting with human blood platelets have the ability to stimulate the release of $\mathrm{NO}$ and to a greater extent $\mathrm{ONOO}^{-}$leading to a low [NO]/ $\left[\mathrm{ONOO}^{-}\right]$ratio that correlated well with the SiNP-induced platelet aggregation. Indeed, we observed that SiNP stimulated GPIIb/IIIa activation and SELP expression and led to platelet aggregation via ADP- and MMP2-dependent mechanisms. All of these effects augmented with increased nanoparticle concentration, but were inversely proportional to the size of SiNP. In fact, the smallest SiNP $(10 \mathrm{~nm})$ induced the most severe effects on platelets. Recently, our studies on the effects of amorphous SiNP on human endothelial cells also reported the role of the $[\mathrm{NO}] /\left[\mathrm{ONOO}^{-}\right]$ratio in the nanoparticle-induced endothelial inflammatory and cytotoxic responses. ${ }^{1}$

Amorphous SiNP have a noncrystalline structure, a high surface-area-to-volume ratio and a large negative surface charge. A high surface-area-to-volume ratio, which decreases in the opposite direction to size, favors the formation of the "protein corona" with fundamental significance for bionanointeractions. The "protein corona" along with fluid characteristics and particle surface area and zeta potentials can affect the formation of nanoparticle agglomerates in the biological environment and may influence nanoparticle toxicity. ${ }^{25,26}$

Our TEM study shows that SiNP interacted with the platelet surface membrane, internalized and distributed within the platelet cytoplasm. The interaction of SiNP with platelet surface membranes raised the possibility that nanoparticles 


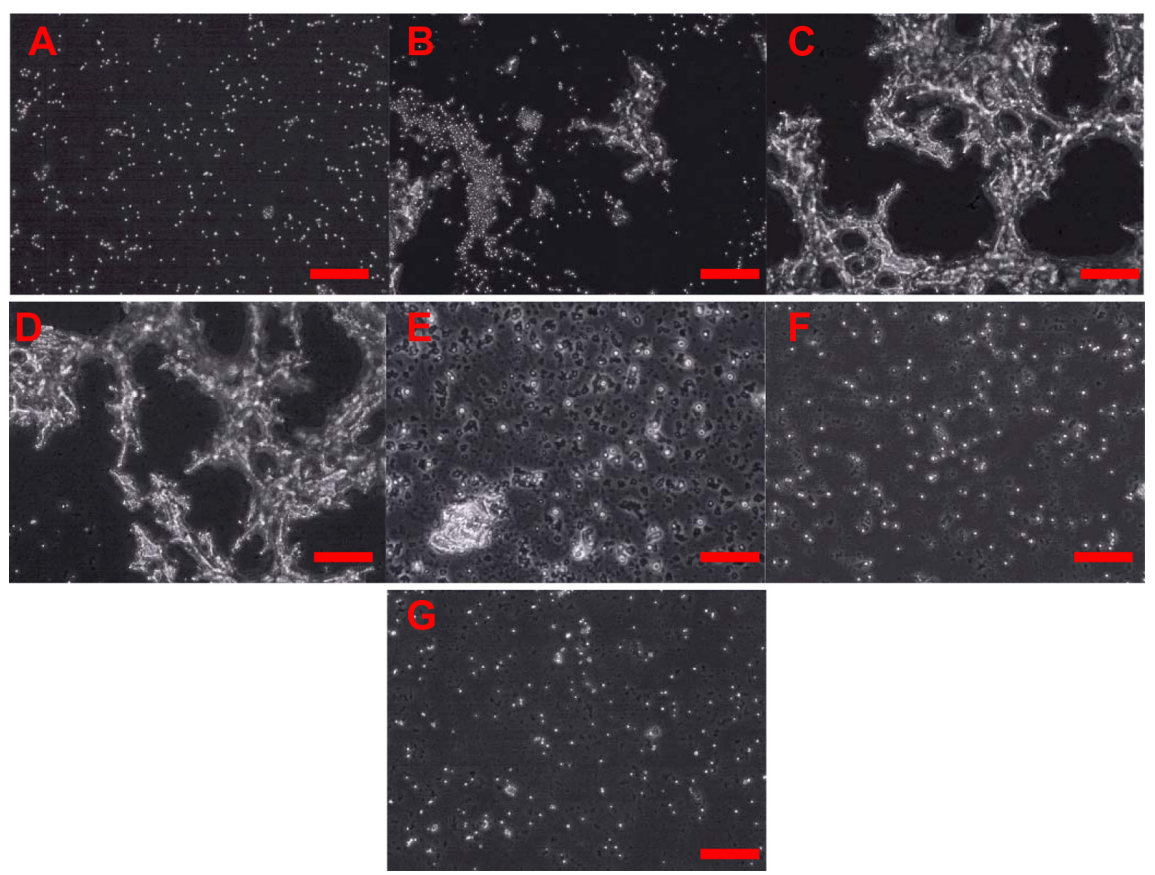

Figure 4 Amorphous SiNP induce platelet aggregation. Platelets were exposed to $10 \mu \mathrm{g} / \mathrm{mL} 10-\mathrm{nm}$ SiNP in the absence (C) or present of inhibitors of platelet aggregation (D-G). Unstimulated (resting) platelets (A) and platelet aggregation induced by collagen (B) are also shown. Previous to the exposure to I0SiNP, platelets were incubated with acetylsalicylic acid (D), phenanthroline $(\mathbf{E})$, apyrase $(\mathbf{F})$ and a mixture of these three inhibitors $(\mathbf{G})$.

Note: Scale bars represent $100 \mu \mathrm{m}$.

Abbreviation: SiNP, silica nanoparticles.

can affect calcium channels as well as the endothelial nitric oxide synthase (eNOS) that is associated with caveolae. ${ }^{27}$ Indeed, there is convincing evidence that modulation of mechanosensitive ion channels involves $\mathrm{NO}$ and $\mathrm{ONOO}^{-28}$ Therefore, we hypothesized that amorphous SiNP collide with the platelet surface membrane leading to opening of calcium channels, and eventually, uncoupling of eNOS. The kinetics of the penetration of the platelet membrane by SiNP most likely involved a flux of calcium ions into the cytoplasm. ${ }^{29}$ Therefore, SiNP are likely to stimulate a calcium-dependent NO release in human platelets. The process of increased and prolonged NO production leads to depletion of enzymatic substrates and cofactors, and eventually, uncoupling of eNOS. ${ }^{30}$ The uncoupled eNOS can generate superoxide ${ }^{10}$ which can rapidly react with $\mathrm{NO}$ to produce $\mathrm{ONOO}^{-}$and change critically the balance of $[\mathrm{NO}] /\left[\mathrm{ONOO}^{-}\right]$. At high level of cytoprotective $\mathrm{NO}$ and/or low level of cytotoxic $\mathrm{ONOO}^{-}$, this ratio is high $(>2.0)$ indicating coupled eNOS and normal endothelial and platelet function. A low ratio $(<1.0)$ is associated with uncoupled eNOS, dysfunctional cardiovascular system and high nitroxidative/oxidative stress. ${ }^{1,9,10}$ Our current experimental results support this hypothesis and show that amorphous SiNP unfavorably shift the $[\mathrm{NO}] /\left[\mathrm{ONOO}^{-}\right]$balance to low levels. There is convincing evidence that platelet aggregation is favored by nitroxidative/oxidative stress induced by $\mathrm{ONOO}^{-}$
${ }^{11,12}$ Indeed, platelet-derived and exogenous $\mathrm{ONOO}^{-}$induce $\mathrm{TXA}_{2}$ formation, ${ }^{31}$ nitration of tyrosine-containing proteins, ${ }^{32}$ SELP expression and GPIIb/IIIa activation. ${ }^{12}$ The activation of GPIIb/IIIa (a change from the low- to high-affinity conformation) and translocation of SELP to the platelet surface membrane is crucial for platelet aggregation to occur. ${ }^{33,34}$ Indeed, GPIIb/IIIa is the major platelet surface transmembrane receptor and it plays an important role in platelet aggregation..$^{35}$ In addition, platelets contain a pool of this glycoprotein stored in $\alpha$-granules ${ }^{36}$ Furthermore, SELP, that is also stored in platelet $\alpha$-granules, mediates platelet-leukocyte aggregation since it is rapidly translocated to the surface upon platelet activation. ${ }^{37}$ Our studies demonstrate that SiNP have the ability to induce GPIIb/IIIa activation and SELP expression on the platelet surface membrane leading to platelet aggregation. Interestingly, carbon nanoparticles, including nanotubes, have a similar ability. ${ }^{38,39}$ The activation of GPIIb/IIIa is triggered off by the release of major platelet activators that mediate pathways of aggregation such as TXA $2,{ }^{13} \mathrm{ADP},{ }^{14}$ and MMP2 ${ }^{15}$ which amplify aggregation. In fact, we have previously shown that MMP2 translocates to the platelet surface during platelet aggregation. ${ }^{40}$ Indeed, it has been also demonstrated the interaction of MMP2 with the integrin $\alpha$ II $\beta$ III on the platelet membrane. ${ }^{41}$ We demonstrate here that SiNP can stimulate platelet aggregation via ADP- and MMP2-dependent mechanisms. 
However, in contrast to agonist-induced aggregation which can be abolished by combination of ASA, apyrase, and phenanthroline, ${ }^{15}$ SiNP-induced aggregation is not completely dependent on the release of TXA ${ }_{2}$, ADP, and MMP2. Interestingly, nanoparticles can directly interact with proteins and ion channels and these effects can also contribute to the profile of SiNP actions on platelets. ${ }^{42,43}$

In conclusion, engineered amorphous SiNP penetrated the platelet plasma membrane and stimulated a rapid and prolonged NO release leading to eNOS uncoupling, $\mathrm{ONOO}^{-}$ over-production and eventually, a low $[\mathrm{NO}] /\left[\mathrm{ONOO}^{-}\right]$ratio and high nitroxidative/oxidative stress. The unfavorable situation, thus produced, favored receptors activation (GPIIb/IIIa) and expression (SELP) on the platelet surface membrane leading to platelet activation and aggregation. Furthermore, SiNP-induced platelet aggregation is mediated via the MMP2 and ADP pathways. Importantly, these effects were all inversely proportional to the amorphous SiNP size and directly proportional to nanoparticle concentration. These findings, along with our study on endothelial cells, ${ }^{1}$ conclusively highlight the importance of $\mathrm{NO} /$ peroxynitrite imbalance in the pathomechanism of nanotoxicological effects of amorphous SiNP with profound implications in the disruption of vascular homeostasis.

\section{Acknowledgments}

This project was funded by a Science Foundation Ireland grant to MWR and a Trinity College Dublin award to JJC. Authors would like to thank Dr Lorraine O'Driscoll, Dr Lidia Tajber, Dr Maria Jose Santos-Martinez, Dr Alan Gaffney, Mr Neal Leddy, Mr Dino Muravec and Ms Neasa Chambers for advice and technical assistance. CM is Science Foundation Ireland Stokes lecturer.

\section{Disclosure}

The authors report no conflicts of interest in this work.

\section{References}

1. Corbalan JJ, Medina C, Jacoby A, Malinski T, Radomski MW. Amorphous silica nanoparticles trigger nitric oxide/peroxynitrite imbalance in human endothelial cells: inflammatory and cytotoxic effects. Int J Nanomedicine. 2011;6:2821-2835.

2. Radomski MW, Palmer RM, Moncada S. The anti-aggregating properties of vascular endothelium: interactions between prostacyclin and nitric oxide. Br J Pharmacol. 1987;92(3):639-646.

3. Radomski MW, Palmer RM, Moncada S. An L-arginine/nitric oxide pathway present in human platelets regulates aggregation. Proc Natl Acad Sci U S A. 1990;87(13):5193-5197.

4. Palmer RM, Ferrige AG, Moncada S. Nitric oxide release accounts for the biological activity of endothelium-derived relaxing factor. Nature. 1987;327(6122):524-526.
5. Malinski T, Radomski MW, Taha Z, Moncada S. Direct electrochemical measurement of nitric oxide released from human platelets. Biochem Biophys Res Commun. 1993;194(2):960-965.

6. Pacher P, Beckman JS, Liaudet L. Nitric oxide and peroxynitrite in health and disease. Physiol Rev. 2007;87(1):315-424.

7. Alonso D, Radomski MW. Nitric oxide, platelet function, myocardial infarction and reperfusion therapies. Heart Fail Rev. 2003;8(1): $47-54$.

8. Poyton RO, Ball KA, Castello PR. Mitochondrial generation of free radicals and hypoxic signaling. Trends Endocrinol Metab. 2009;20(7): 332-340.

9. Heeba G, Hassan MK, Khalifa M, Malinski T. Adverse balance of nitric oxide/peroxynitrite in the dysfunctional endothelium can be reversed by statins. J Cardiovasc Pharmacol. 2007;50(4):391-398.

10. Kalinowski L, Dobrucki IT, Malinski T. Race-specific differences in endothelial function: predisposition of African Americans to vascular diseases. Circulation. 2004;109(21):2511-2517.

11. Villa LM, Salas E, Darley-Usmar VM, Radomski MW, Moncada S. Peroxynitrite induces both vasodilatation and impaired vascular relaxation in the isolated perfused rat heart. Proc Natl Acad Sci U S A. 1994;91(26):12383-12387.

12. Moro MA, Darley-Usmar VM, Goodwin DA, et al. Paradoxical fate and biological action of peroxynitrite on human platelets. Proc Natl Acad Sci U S A. 1994;91(14):6702-6706.

13. Needleman P, Moncada S, Bunting S, Vane JR, Hamberg M, Samuelsson B. Identification of an enzyme in platelet microsomes which generates thromboxane A2 from prostaglandin endoperoxides. Nature. 1976;261(5561):558-560.

14. Born GV. Effects of adenosine diphosphate (ADP) and related substances on the adhesiveness of platelets in vitro and in vivo. $\mathrm{Br} J$ Haematol. 1966;12(1):37-38.

15. Sawicki G, Salas E, Murat J, Miszta-Lane H, Radomski MW. Release of gelatinase A during platelet activation mediates aggregation. Nature. 1997;386(6625):616-619.

16. Radomski M, Moncada S. An improved method for washing of human platelets with prostacyclin. Thromb Res. 1983;30(4):383-389.

17. Radomski A, Stewart MW, Jurasz P, Radomski MW. Pharmacological characteristics of solid-phase von Willebrand factor in human platelets. Br J Pharmacol. 2001;134(5):1013-1020.

18. Radomski A, Jurasz P, Sanders EJ, et al. Identification, regulation and role of tissue inhibitor of metalloproteinases-4 (TIMP-4) in human platelets. Br J Pharmacol. 2002;137(8):1330-1338.

19. Jurasz P, Alonso D, Castro-Blanco S, Murad F, Radomski MW. Generation and role of angiostatin in human platelets. Blood. 2003;102(9): 3217-3223.

20. Malinski T, Taha Z. Nitric oxide release from a single cell measured in situ by a porphyrinic-based microsensor. Nature. 1992;358(6388): 676-678.

21. Brovkovych V, Patton S, Brovkovych S, Kiechle F, Huk I, Malinski T. In situ measurement of nitric oxide, superoxide and peroxynitrite during endotoxemia. J Physiol Pharmacol. 1997;48(4):633-644.

22. Kalinowski L, Malinski T. Endothelial NADH/NADPHdependent enzymatic sources of superoxide production: relationship to endothelial dysfunction. Acta Biochim Pol. 2004;51(2): 459-469.

23. Jurasz P, Stewart MW, Radomski A, Khadour F, Duszyk M, Radomski MW. Role of von Willebrand factor in tumour cell-induced platelet aggregation: differential regulation by $\mathrm{NO}$ and prostacyclin. $\mathrm{Br}$ J Pharmacol. 2001;134(5):1104-1112.

24. Ruggeri ZM, Mendolicchio GL. Adhesion mechanisms in platelet function. Circ Res. 2007;100(12):1673-1685.

25. Lundqvist M, Stigler J, Elia G, Lynch I, Cedervall T, Dawson KA. Nanoparticle size and surface properties determine the protein corona with possible implications for biological impacts. Proc Natl Acad Sci USA. 2008;105(38):14265-14270. 
26. Thomassen LC, Aerts A, Rabolli V, et al. Synthesis and characterization of stable monodisperse silica nanoparticle sols for in vitro cytotoxicity testing. Langmuir. 2010;26(1):328-335.

27. Nishikawa T, Iwakiri N, Kaneko Y, et al. Nitric oxide release in human aortic endothelial cells mediated by delivery of amphiphilic polysiloxane nanoparticles to caveolae. Biomacromolecules. 2009;10(8): 2074-2085.

28. Dyachenko V, Rueckschloss U, Isenberg G. Modulation of cardiac mechanosensitive ion channels involves superoxide, nitric oxide and peroxynitrite. Cell Calcium. 2009;45(1):55-64.

29. Gelderman MP, Simakova O, Clogston JD, et al. Adverse effects of fullerenes on endothelial cells: fullerenol $\mathrm{C} 60(\mathrm{OH}) 24$ induced tissue factor and ICAM-I membrane expression and apoptosis in vitro. Int $J$ Nanomedicine. 2008;3(1):59-68.

30. Huk I, Nanobashvili J, Neumayer C, et al. L-arginine treatment alters the kinetics of nitric oxide and superoxide release and reduces ischemia/reperfusion injury in skeletal muscle. Circulation. 1997;96(2): 667-675.

31. Schildknecht S, van der Loo B, Weber K, Tiefenthaler K, Daiber A, Bachschmid MM. Endogenous peroxynitrite modulates PGHS-1dependent thromboxane A2 formation and aggregation in human platelets. Free Radic Biol Med. 2008;45(4):512-520.

32. Naseem KM, Khan J, Jacobs M, Bruckdorfer KR. Nitration of platelet cytosolic proteins by peroxynitrite. Biochem Soc Trans. 1997;25(3): $397 \mathrm{~S}$.

33. Coller BS. Blockade of platelet GPIIb/IIIa receptors as an antithrombotic strategy. Circulation. 1995;92(9):2373-2380.

34. Radomski MW, Radomski AS. Regulation of blood cell function by the endothelial cells. In: Vallance PJT, Wallance DJ, editors. Vascular Endothelium in Human Physiology and Pathophysiology. London, UK: Harwood Academic Publishers; 2000:95-106.
35. Shattil SJ, Kashiwagi H, Pampori N. Integrin signaling: the platelet paradigm. Blood. 1998;91(8):2645-2657.

36. Wagner CL, Mascelli MA, Neblock DS, Weisman HF, Coller BS, Jordan RE. Analysis of GPIIb/IIIa receptor number by quantification of 7E3 binding to human platelets. Blood. 1996;88(3):907-914.

37. Andrews RK, Berndt MC. Platelet physiology and thrombosis. Thromb Res. 2004;114(5-6):447-453.

38. Radomski A, Jurasz P, Alonso-Escolano D, et al. Nanoparticleinduced platelet aggregation and vascular thrombosis. Br J Pharmacol. 2005;146(6):882-893

39. Bihari P, Holzer M, Praetner M, et al. Single-walled carbon nanotubes activate platelets and accelerate thrombus formation in the microcirculation. Toxicology. 2010;269(2-3):148-154.

40. Sawicki G, Sanders EJ, Salas E, Wozniak M, Rodrigo J, Radomski MW. Localization and translocation of MMP-2 during aggregation of human platelets. Thromb Haemost. 1998;80(5):836-839.

41. Choi WS, Jeon OH, Kim HH, Kim DS. MMP-2 regulates human platelet activation by interacting with integrin alphaIIbbeta3. J Thromb Haemost. 2008;6(3):517-523.

42. McCarthy J, Gong X, Nahirney D, Duszyk M, Radomski M. Polystyrene nanoparticles activate ion transport in human airway epithelial cells. Int J Nanomedicine. 2011;6:1343-1356.

43. Cedervall T, Lynch I, Lindman S, et al. Understanding the nanoparticleprotein corona using methods to quantify exchange rates and affinities of proteins for nanoparticles. Proc Natl Acad Sci U S A. 2007;104(7): 2050-2055.
International Journal of Nanomedicine

\section{Publish your work in this journal}

The International Journal of Nanomedicine is an international, peerreviewed journal focusing on the application of nanotechnology in diagnostics, therapeutics, and drug delivery systems throughout the biomedical field. This journal is indexed on PubMed Central, MedLine, CAS, SciSearch $₫$, Current Contents $₫ /$ Clinical Medicine,

\section{Dovepress}

Journal Citation Reports/Science Edition, EMBase, Scopus and the Elsevier Bibliographic databases. The manuscript management system is completely online and includes a very quick and fair peer-review system, which is all easy to use. Visit http://www.dovepress.com/ testimonials.php to read real quotes from published authors. 